\title{
ANALISIS SISTEM MANAJEMEN PEKERJAAN BERBASIS WEB UNTUK MENUNJANG AKUNTABILITAS KINERJA DI BPS PROVINSI SULAWESI TENGGARA
}

\author{
Fatchur Rochman \\ Badan Pusat Statistik Provinsi Sulawesi Tenggara \\ Email: fatoer@bps.go.id
}

(Naskah masuk: dd mmm yyyy, diterima untuk diterbitkan: dd mmm yyyy)

\begin{abstract}
Abstrak
Reformasi di bidang manajemen pekerjaan terus berlanjut di Badan Pusat Statistik (BPS), demikian halnya juga di BPS Provinsi Sulawesi Tenggara. BPS Provinsi Sulawesi Tenggara pada tahun 2016 membuat suatu portal berbasis web dengan tujuan agar dapat diakses kapan saja dan dimana saja oleh seluruh pegawai. Selain itu, para pimpinan dapat memantau kegiatan seluruh pegawai secara real time. Dalam portal ini terdapat beberapa sistem yang digunakan untuk membantu kelancaran kegiatan pegawai dalam menjalankan tugasnya setap hari. Kajian ini menggunakan model dashboard sebagai sistem monitoring kinerja pegawai BPS se-Sulawesi Tenggara untuk melihat sejauh mana pemanfaatan sistem yang telah dibuat berhubungan dengan akuntabilitas kinerja pegawai. Analisis model dashboard dilakukan dengan mengolah 180 data pengguna daily reborn yang telah dikumpulkan. Hasil penelitian menunjukkan bahwa sistem manajemen pekerjaan berbasis web BPS Provinsi Sulawesi Tenggara dapat diakses dan mampu mengetahui kinerja pegawai yang dapat ditampilkan dalam bentuk tabel, grafik dan dashboard. Hal ini ditunjukkan melalui persepsi pengguna menunjukkan kebermanfaatan pengguna dashboard daily reborn telah mencapai 84,03 persen, persepsi pengguna menunjukkan kemudahan pengguna dashboard daily reborn mencapai 86,93 persen, intensitas penggunaan daily reborn mencapai 84,09 persen dan sikap penggunaan dashboard daily reborn mencapai 89,74 persen.
\end{abstract}

Kata kunci: Manajemen Pekerjaan, Dashboard, Daily Reborn

\section{WEB-BASED JOB MANAGEMENT SYSTEM ANALYSIS TO SUPPORT PERFORMANCE ACCOUNTABILTY AT BPS-STATISTICS OF SULAWESI TENGGARA PROVINCE}

\begin{abstract}
The Reforms in the field of job management are still being held at Statistics Indonesia (BPS), as well as at the BPS-Statistics Sulawesi Tenggara Province. BPS-Statistics Sulawesi Tenggara Province in 2016 has created a web-based portal with a purpose to make it accesible anytime and anywhere by all employees. In addition, the leaders can monitor the activities of all employees in real time. In this portal, there are several systems that are used to assist the activities of employees in carrying out their daily duties. This study used a dashboard model as a monitoring system of office employees' performance in BPS-Statistics Sulawesi Tenggara Province to see how far the utilization of the system that has been made is related to the accountability of employee performance. The dashboard model analysis is carried out by processing 180 users of daily reborn that has been collected. The results showed that the web-based job management system of the BPS-Statistics Sulawesi Tenggara Province is accessible and able to show the employee performance which can be displayed in the form of tables, graphs and dashboards. This result can be known by user perceptions that showed the usefulness of daily reborn dashboard has reached 84.03 percent, the ease of daily reborn dashboard has reached 86.93 percent, daily reborn usage intensity has reached 84.09 percent and the daily reborn dashboard usage attitudes has reached 89.74 percent.
\end{abstract}

Keywords: Job Management, Dashboard, Daily Reborn

\section{PENDAHULUAN}

Pesatnya perkembangan teknologi informasi saat ini mengakibatkan informasi mudah didapatkan oleh siapa saja [1]. Tak hanya itu, pemanfaatan teknologi yang ada diharapkan mampu mengelola informasi menjadi lebih yang efektif dan efisien [2]. Dengan Informasi yang efektif dan efisien, tentunya 
sebuah perusahaan atau organisasi dapat lebih mudah mencapai tujuannya. Dengan kata lain adanya teknologi membantu organisasi atau perusahaan untuk melakukan berbagai upaya meningkatkan kinerjanya dalam hal untuk pencapaian tujuannya [3].

Keberhasilan pencapaian tujuan perusahaan atau organisasi juga tidak terlepas dari sumber daya manusia yang ada. Sumber daya manusia dalam suatu organisasi harus dikelola dengan baik melalui suatu manajemen yang teratur agar tercipta akuntabilitas. Pengelolaan sumber daya manusia dalam organisasi dapat diukur melalui kinerja yang digambarkan sebagai suatu penilaian terhadap pegawai akan tugas yang diberikan [4]. Dengan demikian, sangat penting adanya manajemen kinerja pada semua organisasi. Salah satu bentuk manajemen kinerja yaitu manajemen pekerjaan dimana setiap pegawai harus mampu mengelola setiap pekerjaan yang diberikan oleh atasannya dan sebaliknya setiap atasan harus mampu melakukan pengawasan terhadap bawahannya. Hal ini tentunya harus didukung oleh sistem manajemen yang mampu efektif dan efisien.

Reformasi di bidang manajemen pekerjaan terus berlanjut di Badan Pusat Statistik (BPS), demikian halnya juga di BPS Provinsi Sulawesi Tenggara. BPS Provinsi Sulawesi Tenggara sebagai salah satu satker yang telah mencapai predikat WBK dari Kemenpan RB, berupaya semaksimal mungkin melakukan efisiensi dan efektifitas pekerjaan melalui penerapan teknologi informasi menuju predikat WBBM. Saat ini, BPS Provinsi Sulawesi Tenggara telah mengembangkan beberapa aplikasi yang dihimpun dalam Portal Sultradata (sultradata.com). Secara umum portal berbasis web dibuat dengan tujuan agar dapat diakses kapan saja dan dimana saja oleh seluruh pegawai. Selain itu, para pimpinan dapat memantau kegiatan seluruh pegawai secara real time. Dalam portal ini terdapat beberapa sistem yang digunakan untuk membantu kelancaran kegiatan pegawai dalam menjalankan tugasnya setap hari.

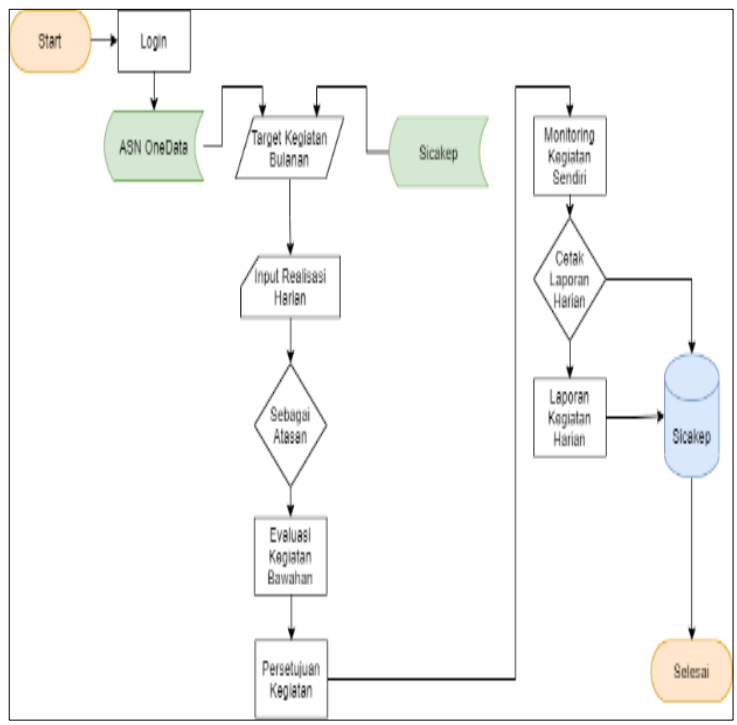

Gambar 1. Flowchart Aplikasi Daily Reborn terintegrasi dengan One Data ASN dan SiCakep
Salah satu aplikasi yang dikembangkan adalah Daily Reborn. Aplikasi Daily Reborn pada awalnya hanyalah aplikasi untuk mencatat kegiatan-kegiatan yang dilaksanakan setiap harinya oleh masingmasing pegawai, namun pada perkembangannya telah banyak mengalami kemajuan diantaranya sudah terintegrasi dengan aplikasi lainnya seperti One Data ASN dan SiCakep.Mengingat pentingnya sistem manajemen seperti Aplikasi Daily Reborn untuk mendukung peningkatan kinerja di BPS Sulawesi Tenggara maka diperlukan sebuah kajian untuk melihat sejauh mana pemanfaatan sistem yang telah dibuat tersebut. Beberapa penelitian terkait pemanfaatan sistem informasi untuk manajemen pekerjaan telah banyak dilakukan diantaranya oleh [1] mengenai Penerapan Sistem Informasi Manajemen dan Pengawasannya di Kantor Pelayanan Pajak Pratama Manado, kemudian oleh [2] mengenai Aplikasi Pendukung Kinerja Karyawan di Mitra Dinamika Konsultan, serta oleh [3] terkait Penerapan Sistem Manajemen Kinerja Pegawai di Bandara Udara Laga Ligo Bua Kabupaten Luwu. Namun studi penelitian pemanfaatan sistem tersebut masih terbatas pada sistem manajemen pekerjaan saja dan belum menghubungkan antara pemanfaatan sistem manajemen pekerjaan dengan akuntabilitas kinerja pegawai.

Oleh karena itu, penulis tertarik untuk menganalisis pemanfaatan sistem manajemen pekerjaan berbasis web pada aplikasi Daily Reborn dengan menggunakan model dashboard. Hal ini mengingat tuntutan agar capaian kinerja dari seluruh pegawai dapat dipertangung jawabkan secara akuntabel, sehingga diperlukan suatu sistem yang dapat mendokumentasikan kegiatan yang telah dikerjakan dan merencanakan kegiatan-kegiatan yang akan datang agar kegiatan lebih efektif dan efisien. Model dashboard merupakan model yang menyediakan informasi kualitas kinerja dari suatu organisasi atau perusahaan [5]. Model ini mampu membantu manager untuk mengukur dan menganalisis sistem yang ada dengan mengintegrasikan dengan berbagai informasi yang tersedia [6].

\section{METODE PENELITIAN}

Metode penelitian yang digunakan berfokus pada beberapa tahapan besar seperti identifikasi kebutuhan, analisis, dan hasil [7]. Penelitian ini juga mempertimbangkan hasil dari penelitian terdahulu mengenai penggunaan model dashboard [8]. 


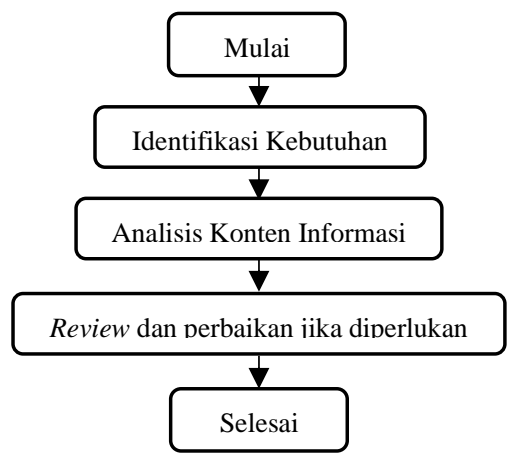

Gambar 2. Prosedur Penelitian

Perancangan model dashboard manajemen pegawai terdiri dari beberapa tahapan yang harus dilaksanakan untuk menjamin hasil yang baik sesuai dengan yang diharapkan. Langkah awal dari penelitian ini dilakukan dengan melakukan identifikasi terkait kebutuhan sistem yang dimulai dengan pengumpulan data awal. Selanjutnya masuk ke tahapan analisis dimana dilakukan dengan menganalisis isi dashboard dan penerimaan sistem daily reborn yang telah ada. Tahapan terakhir yaitu melakukan review hasil serta perbaikan jika diperlukan. Prosedur penelitian yang dilakukan dalam penelitian ini dapat dilihat pada Gambar 2 .

Langkah-langkah yang digunakan pada penelitian ini sudah senada dengan tahapan pada proses business intelligence secara umum yaitu pengidentifikasian masalah yang ada, pengidentifikasian lokasi, pengumpulan dan pengolahan data, serta penyimpanan dan pemasangan aplikasi [9].

Dalam melakukan review dan perbaikan diperlukan sebuah ukuran yang memungkinkan mengetahui tingkat penerimaan pengguna terhadap dashboard daily reborn. Untuk mengetahui lebih jauh mengenai penerimaan sistem dashboard daily reborn, ada beberapa indikator yang dilakukan analisis diantaranya

a. Persepsi kemudahan penggunaan merupakan konsep sejauh mana pengguna merasakan kemudahan ataupun kesulitan dari aktivitas penggunaan sistem dashboard daily reborn. Persepsi kemudahan penggunaan berkaitan dengan beberapa indikator diantaranya navigasi, presentasi, kenyamanan dan kemudahan yang dimiliki oleh suatu website [10].

b. Persepsi kebermanfaatan sistem berkaitan dengan dua hal penting yaitu produktifitas dan efektifitas sistem dari kegunaan suatu website dalam rangka untuk peningkatan kinerja pengguna yang menggunakan sistem tersebut [11]. Beberapa indikator dari persepsi diatas diantaranya: kecepatan pekerjaan, peningkatan produktifitas kerja, peningkatan kinerja, efektifitas tugas, dan banyak lainnya.

c. Sikap terhadap penggunaan sistem dashboard daily reborn merupakan sikap pengguna terhadap penggunaan sistem dashboard daily reborn sebagai evaluasi pemakai tentang penerimaan terhadap sistem yang ada [12]. Jadi dalam konteks sikap ini, pengguna akan memperlihatkan sikapnya apakah pengguna tersebut menerima ataupun menolak terhadap sistem dashboard daily reborn tersebut.

d. Intensitas perilaku pengguna sistem dashboard daily reborn merupakan niat perilaku pengguna untuk menggunakan sistem informasi yang ada, sehingga menjadi kecenderungan perilaku untuk tetap menggunakan sistem dashboard daily reborn tersebut [13]. Inilah yang disebut fase penerimaan, karena pengguna menunjukkan sikap penerimaan terhadap penggunaan sistem dashboard daily reborn. Adanya niat positif pengguna untuk menggunakan sistem dashboard daily reborn diyakini akan mampu menggerakkan pengguna dalam menggunakan sistem dashboard daily reborn.

e. Penggunaan sistem dashboard daily reborn secara aktual menggambarkan kondisi secara nyata penggunaan sistem informasi tersebut [14]. Indikator ini menggambarkan seberapa banyak pengguna sistem daily reborn yang intens atau pengguna dengan frekuensi yang tinggi serta digunakan secara terus menerus.

f. Penerimaan (acceptance) ini sebenarnya meliputi variabel intensitas perilaku penggunaan sistem dashboard daily reborn dan penggunaan sistem dashboard daily reborn secara aktual. Penerimaan ini berarti perlu mengetahui apakah teknologi yang dimaksud yaitu sistem dashboard daily reborn benar-benar diterima oleh pengguna ternasuk kesediaan menggunakan teknologi untuk menunjang tugas yang ada [15]. Selain itu, Penerimaan sistem seperti dashboard daily reborn oleh pengguna sangat penting untuk menjamin keberlangsungan sistem tersebut, sebab hal itu terkait keyakinan pengguna untuk menggunakan atau tidak sistem tersebut [16].

\section{HASIL DAN PEMBAHASAN}

\subsection{Hasil Penelitian}

Penelitian ini menghasilkan sebuah model sistem manajemen pekerjaan berbasis web untuk menunjang akuntabilitas kinerja pegawai BPS Se Sulawesi Tenggara. Input dari sistem berupa data isian uraian kegiatan harian pegawai BPS se Sulawesi Tenggara sebanyak 180 data. Data monitoring model sistem manajemen pekerjaan berbasis web dapat dianalisis dengan menggunakan alat statistik. Hasil pengolahan data dan analisis berupa dashboard sistem informasi disajikan dalam bentuk grafik, tabel dan dashboard.

\subsection{Antarmuka Model Dashboard}

Monitoring dashboard manajemen kinerja model berbasis web dibutuhkan sebuah perancangan 
antarmuka suatu web agar pengguna aplikasi mengetahui dan menggunakan model dashboard monitoring yang tersedia. Tampilan yang muncul ketika sistem ini dijalankan adalah halaman utama dashboard monitoring pada gambar 3 dan halaman login untuk aplikasi daily reborn pada gambar 4.
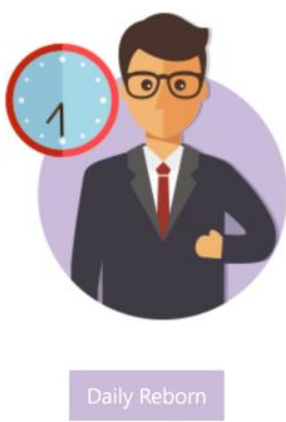

Pencatatan kegiatan harian pegawai BPS se-Provinsi Sulawesi Tenggara нЕ
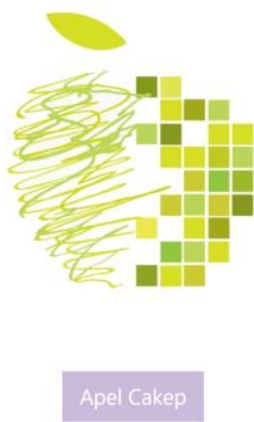

Aplikasi Penilaian Capaian Kinerja Pegawai Bulanan
Gambar 3. Halaman Utama Dashboard

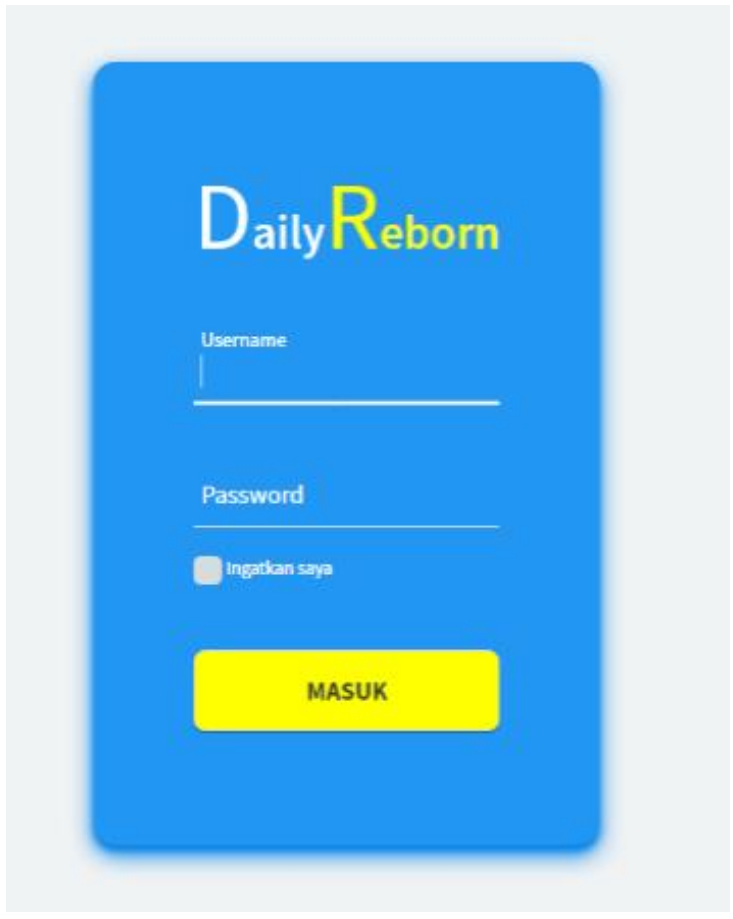

Gambar 4. Tampikan Login Aplikasi Daily Reborn

Aplikasi Daily reborn memiliki 3 fungsi yaitu fungsi pengentrian kegiatan bagi staf, persetujuan kegiatan bagi koordinator fungsi, dan fungsi monitoring bagi pimpinan. Adapun tampilan user interface dashboard dapat dilihat pada gambar 5 dimana memperlihatkan tutorial penggunaan aplikasi dan reminder kegiatan harian.

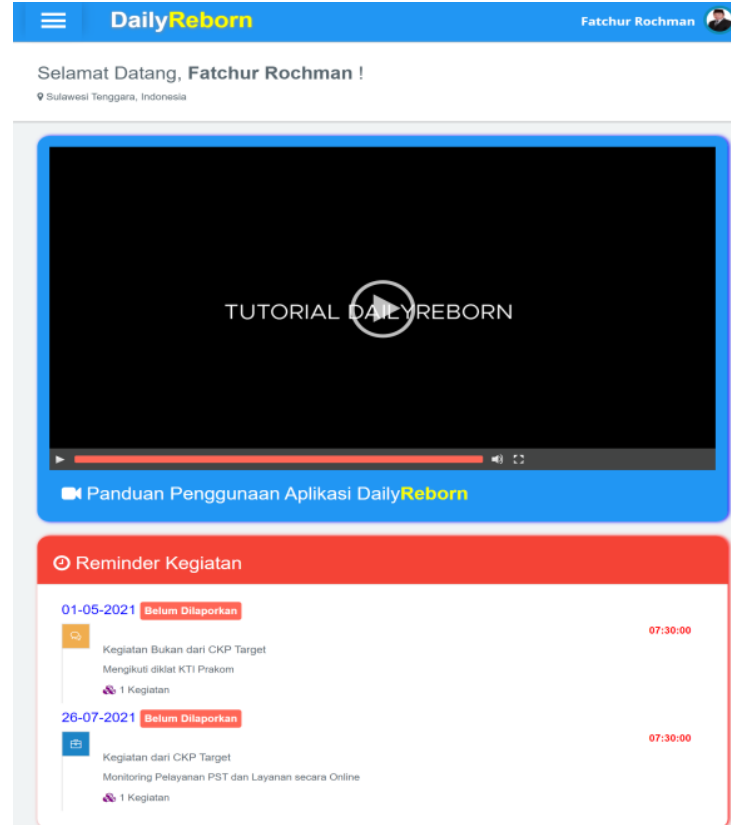

Gambar 5. Tampikan user interface dashboard aplikasi Daily Reborn

Selanjutnya fungsi pertama pada aplikasi daily reborn untuk mulai melakukan entri aktivitas harian dapat dilihat pada gambar 6 yang menunjukkan lembar aktivitas harian yang telah diisi dalam 1 bulan kerja.

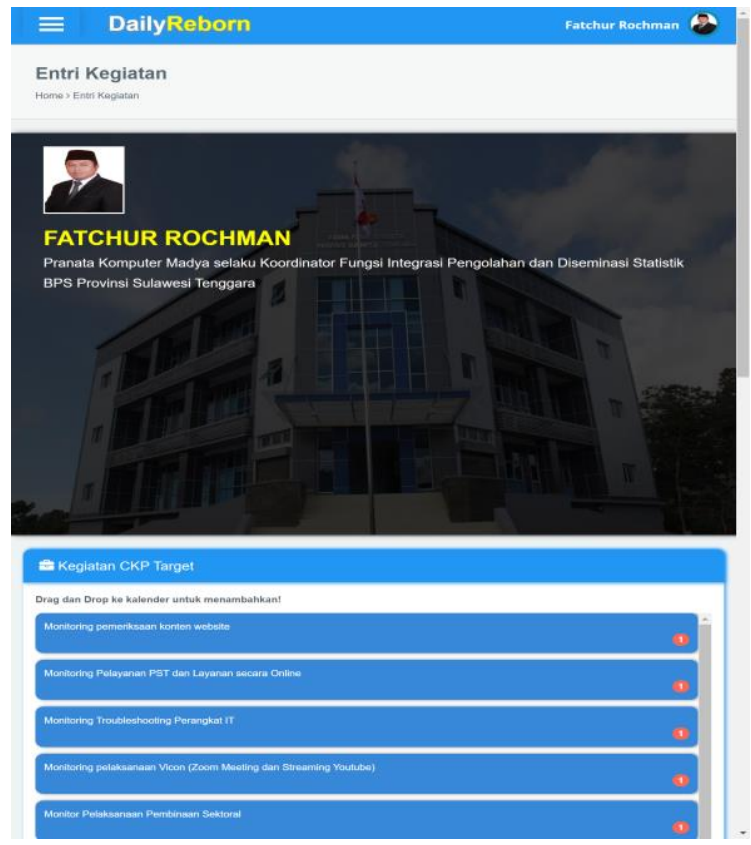

Gambar 6. Tampikan entri aktivitas harian aplikasi Daily Reborn

Gambar 7 memperlihatkan tampilan persetujuan kegiatan oleh koordinator fungsi terhadap bawahannya. Hal ini dibuat agar aktivitas staf atau bawahan yang akan dilakukan senantiasa diketahui oleh atasannya sehingga manajemen pekerjaan dapat dikelola dengan baik oleh para pimpinan. 


\section{$\equiv$}

DailyReborn

Selamat Datang, Fatchur Rochman !

QSulawesi Tenggura, Indonesesa

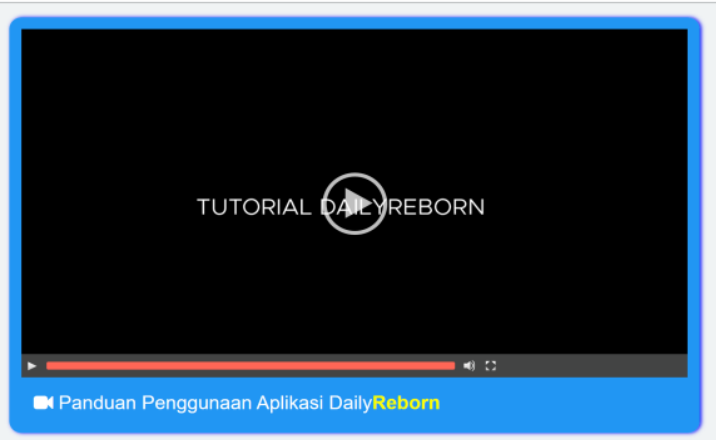

\section{O Reminder Kegiatan}

01-05-2021 Belum Dilaporkan

B)

Kogitatan Bukan dari CKP Targe

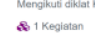

26-07-2021 Belum Diliaporkan

숩

Keglatan dari CKP Target

S. 1 Keglatan

Gambar 7. Tampilan persetujuan aktivitas harian aplikasi Daily Reborn

Selanjutnya pada gambar 8 terdapat tampilan yang menunjukkan monitoring pengisian aktivitas harian bawahan periode 1 bulan. Dengan adanya monitoring maka seluruh aktivitas yang telah dikerjakan dapat diketahui telah dilaporkan atau tidak.

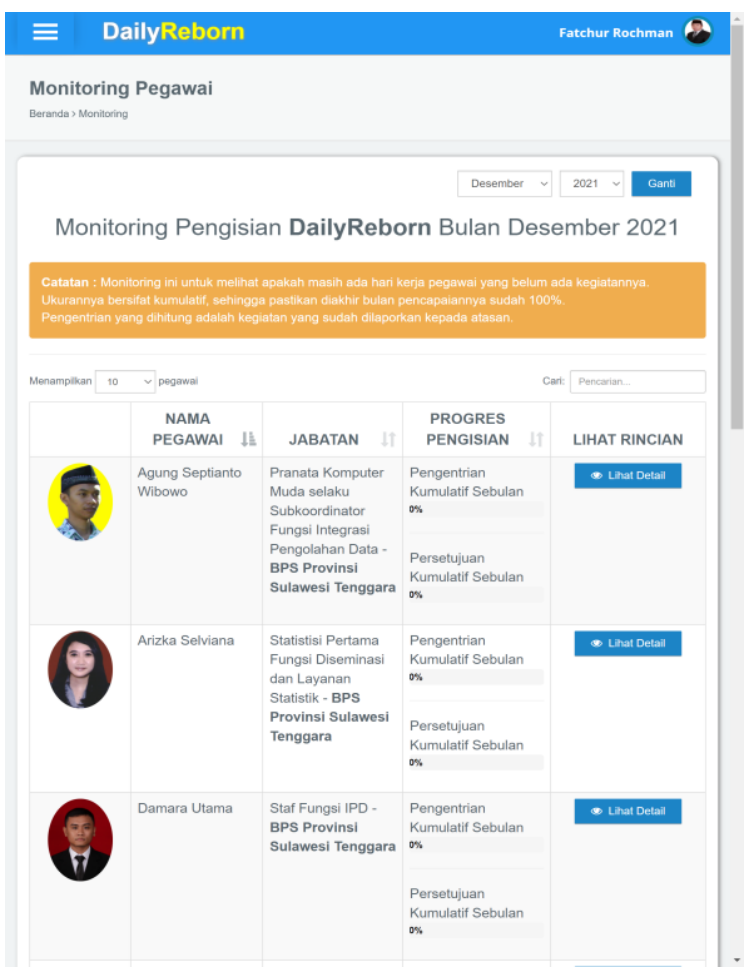

Gambar 8. Tampilan monitoring bagi pimpinan pada aplikasi Daily Reborn

\subsection{Persepsi Pengguna Terhadap Sistem Dashboard Daily Reborn}

Hasil pengujian terhadap persepsi pengguna menunjukan bahwa tingkat penerimaan yang baik terhadap penggunaan dashboard daily reborn. Hal ini terlihat dari tingkat kepuasan terhadap indikator persepsi terhadap kegunaan (Percieved Usefulness), kemudahan (Percieved Ease of Use), intensitas penggunaan (Behavioral Intention), dan sikap penggunaan(Use Behavior).

Berdasarkan tabel 1 diketahui secara umum persepsi pengguna terhadap kegunaan dashboard daily reborn sudah baik. Hal ini terlihat dari unsurunsur yang dinilai meliputi persepsi bahwa penggunaan daily reborn bisa meningkatkan kinerja, meningkatkan produktifitas, menambah efektifitas, bermanfaat, mempermudah pekerjaan, dan mempermudah pekerjaan. Dari hasil penilaian pengguna diperoleh bahwa persepsi pengguna menurut masing-masing unsur penilaian rata-rata sudah diatas 82 persen. Sehingga persepsi kepuasan terhadap kegunaan dashboard daily reborn mencapai $84,03 \%$.

\begin{tabular}{llcc}
\multicolumn{5}{c}{ Tabel 1. Persepsi Pengguna Terhadap Kegunaan } \\
Dashboard Daily Reborn
\end{tabular}

\begin{tabular}{llcc}
\multicolumn{5}{c}{ Tabel 2. Persepsi Pengguna Terhadap Kemudahan } \\
Dashboard Daily Reborn
\end{tabular}

Berdasarkan tabel 2 diketahui secara umum persepsi pengguna terhadap kemudahan dashboard daily reborn sudah baik. Hal ini terlihat dari unsurunsur yang dinilai meliputi persepsi bahwa penggunaan daily reborn jelas dan mudah dipahami; mudah digunakan; memenuhi keinginan; dapat dikontrol; mudah menjadi terampil; serta mudah dipelajari. Dari hasil penilaian pengguna diperoleh bahwa persepsi pengguna menurut masing-masing unsur penilaian rata-rata sudah diatas 82 persen. 
Secara keseluruhan persepsi kepuasan terhadap kemudahan dashboard daily reborn mencapai $86,93 \%$.

\begin{tabular}{|c|c|c|c|}
\hline No & Unsur Penilaian & Nilai Mutu & $\begin{array}{l}\text { Indeks } \\
\text { (Persen) }\end{array}$ \\
\hline (1) & (2) & (3) & (4) \\
\hline 1 & Berniat Menggunakan & 4,23 & 84,55 \\
\hline 2 & Tetap Menggunakan & 4,19 & 83,86 \\
\hline 3 & Tertarik Menggunakan & 4,19 & 83,86 \\
\hline \multicolumn{2}{|c|}{ Intensitas penggunaan } & 4,20 & 84,09 \\
\hline
\end{tabular}

Berdasarkan tabel 3 diketahui secara umum intensitas penggunaan dashboard daily reborn sudah baik. Hal ini terlihat dari unsur-unsur yang dinilai bahwa pengguna tertarik menggunakan, berniat menggunakan, dan tetap menggunakan. Dari hasil penilaian pengguna diperoleh bahwa intensitas penggunaan terhadap dashboard daily reborn menurut masing-masing unsur penilaian rata-rata sudah diatas 83 persen. Sehingga intensitas penggunaan dashboard daily reborn mencapai $84,09 \%$.

Tabel 4. Penggunaan Aktual (Penerimaan) Dashboard

\begin{tabular}{lccc}
\multicolumn{3}{c}{ Daily Reborn } \\
\hline No & Unsur Penilaian & Nilai Mutu & $\begin{array}{c}\text { Indeks } \\
\text { (Persen) }\end{array}$ \\
\hline$(1)$ & (2) & $(3)$ & $(4)$ \\
1 & Telah Menggunakan & 4,50 & 90,10 \\
2 & Selalu Menggunakan & 4,58 & 91,51 \\
3 & Puas Menggunakan & 4,38 & 87,62 \\
Sikap penggunaan & 4,49 & 89,74
\end{tabular}

Berdasarkan tabel 4 diketahui secara umum sikap penggunaan pengguna terhadap dashboard daily reborn sudah baik. Hal ini terlihat dari unsurunsur yang dinilai bahwa pengguna telah menggunakan, selalu menggunakan, dan puas saat menggunakannya. Dari hasil penilaian pengguna diperoleh bahwa sikap penggunaan terhadap dashboard daily reborn menurut masing-masing unsur penilaian rata-rata sudah diatas 87 persen. Sehingga secara keseluruhan sikap penggunaan pengguna terhdap dashboard daily reborn mencapai $89,74 \%$.

\section{KESIMPULAN}

Dari hasil perancangan model sistem manajemen pekerjaan berbasis web dapat disimpulkan bahwa model dashoard monitoring pekerjaan dapat diakses oleh seluruh pegawai di BPS Provinsi Sulawesi Tenggara. Model dashboard monitoring pekerjaan menghasilkan dapat mengetahui kinerja pegawai yang ditampilkan dalam bentuk tabel, grafik dan dashboard.

Hasil analisis menggunakan model dashboard menujukkan bahwa model tersebut dapat dijadikan acuan sebagai parameter dalam menilai kinerja pegawai di BPS Provinsi Sulawesi Tenggara. Persepsi pengguna menunjukan kebermanfaatan penggunaan dashboard daily reborn telah mencapai 84,03 persen. Persepsi pengguna menunjukan kemudahan penggunaan dashboard daily reborn telah mencapai 86,93 persen. Intensitas penggunaan dashboard daily reborn mencapai 84,09 persen. Sedangkan sikap penggunaan dashboard daily reborn mencapai 89,74 persen.

Kedepan diharapkan model dashboard manajemen pegawai dapat terus dikembangkan. Salah satunya adalah kemampuan dalam melakukan perankingan kinerja pegawai secara real time.

\section{DAFTAR PUSTAKA}

[1] B. J. Kaleb, V. P. K. Lengkong and R. N Taroreh. 2019. "Penerapan Sistem Informasi Manajemen dan Pengawasannya di Kantor Pelayanan Pajak Pratama Manado"., Jurnal EMBA (Riset Ekonomi, Manajemen, Bisnis dan Akutansi), Vol. 7 No.1, pp. 781-790. Doi: 10.35794/emba.v7i1.22555

[2] N. R. Radliya and E. Hermawan. 2015. "Aplikasi Pendukung Kinerja Karyawan di Mitra Dinamika Konsultan"., Jurnal Manajemen Informatika (JAMIKA), vol. 5 No.2, pp. 81-95. Doi: 10.34010/jamika.v5i2.651

[3] K. Damayanti, Mappamiring and M. Karim. 2017. "Penerapan Sistem Manajemen Kinerja Pegawai Di Bandara Udara Laga Ligo Bua Kabupaten Luwu"., Jurnal Administrasi Publik, Vol. 3(2), pp. 228-245. Doi: 10.26618/kjap.v3i2.904

[4] R. Ardianwiliandri, R.Y. Efranto and A. Handini. 2018. "Pengukuran Kinerja Sumber Daya Manusia Dengan Pendekatan Human Resources Scorecard"., Jurnal Ilmiah Teknik Industri, Vol 6. No. 3, pp. 185-194. Doi: 10.24912/jitiuntar.v6i3.4244

[5] Ilhamsyah and S. Rahmayuda. 2017. "Perancangan Model Dashboard untuk Monitoring Evaluasi Mahasiswa"., Jurnal Pengembangan IT (JPIT), Vol 2. No. 1, pp. 1317. Doi: 10.30591/jpit.v2i1.436

[6] A. M. R. Wajong. 2015. "Applying Performance Dashboard in Hospitals"., International Journal of Software Engineering and Its Applications, Vol 9. No. 1, pp. 213-220.

[7] E. Hariyanti, I. Werdiningsih and K. Surendro 2011. "Model Pengembangan Dashboard Untuk Monitoring dan Evaluasi Kinerja Perguruan Tinggi”., Jurnal Ilmiah Teknologi Informasi (JUTI), Vol 9(1), pp. 13-20. Doi: 10.12962/j24068535.v9i1.a63

[8] S. Malik. 2005. Enterprise dashboards : Design and best practices for IT. John Wiley \& Sons, Inc., Hoboken, New Jersey

[9] W. W. Eckersone. 2006. Performance dashboards : Measuring, Monitoring and Managing Your Busines. John Wiley \& Sons, Inc., Hoboken, New Jersey 
[10] R. S. N. Faradila and H. Soesanto. 2016. "Analisis Pengaruh Persepsi Kemudahan Penggunaan dan Persepsi Manfaat Terhadap Minat Beli dengan Kepercayaan Sebagai Variabel Intervening (Studi pada Pengunjung Toko Online berrybenka.com di Kalangan Mahasiswa Universitas Diponegoro". Diponegoro Journal of Management, Vol.5 No.3, pp. 239-250, Tersedia melalui: <https:// ejournal3.undip.ac.id/index.php/djom/article/vi ew/14193 > [Diakses 31 April 2021]

[11] Irmadhani. 2012. "Pengaruh Persepsi Kebermanfaatan, Persepsi Kemudahan dan Computer Self Efficacy, terhadap Penggunaan Online Banking pada Mahasiswa S1 Fakultas Ekonomi Universitas Negeri Yogyakarta"., Kajian Pendidikan Akutansi Indonesia, Vol.1 No.3, Tersedia melalui: <https:// https://journal.uny.ac.id/index.php/jkpai/article/ view/882> [Diakses 31 April 2021]

[12] P. N. C. D. Vidantika and I. M. P. D Putra. 2018. "Analisis TAM terhadap Sikap Penggunaan Sistem Informasi Akuntansi Penggajian di PT Garuda Indonesia Station DPS"., Jurnal Akuntansi Universitas Udayana, Vol 24. No. 2, pp. 1105-1134. Doi: 10.24843/EJA.2018.v24i02.p11

[13] K. R. Amanda and M. M. D. Restuti. 2017. "Faktor-faktor yang Mempengaruhi Niat Penggunaan Sistem Informasi Terkomputerisasi pada UKM (Pendekatan Theory of Planned Behavior)"., Jurnal Akuntansi Maranatha, Vol. 9 No. 1, pp. 23-33. Doi: 10.28932/Jam.v9i1.489

[14] S. B. Hermanto and Patmawati. 2017. "Determinan Penggunaan Aktual Perangkat Lunak Akuntansi Pendekatan Technology Acceptance Model'., Jurnal Akuntansi dan Keuangan, Vol. 19 No. 2, pp. 67-81. Doi: 10.9744/jak.19.2.67-81

[15] E. Fatmawati. 2015. "Technology Acceptance model (TAM) untuk menganalisis penerimaan terhadap system informasi Perpustakaan"., Jurnal Iqra : Jurnal Perpustakaan dan Informasi, Vol. 9 No. 1, Tersedia melalui: <https://moraref.kemenag.go.id/documents/arti cle/25457176814292550> [Diakses 31 April 2021]

[16] I. A. G. R. W. Astari and I. N. T. Putra. 2021. "Analisis Sistem Informasi Kemdikbud pada SD Negeri 2 Dawan Klod Dengan System Usability Scale"., JIKO (Jurnal Informatika dan Komputer), Vol.4 No.1, pp. 23-30. Doi: 10.33387/jiko.v4i1 